\title{
QUALITY IN HIGHER EDUCATION IN PORTUGAL THE A3ES CERTIFYING ENTITY: ACCREDITATION OF IQAS AND INSTITUTIONAL ACCREDITATION AT ONE PORTUGUESE UNIVERSITY
}

\author{
N. Jesus-Silva, A. Machado, J. Caramelo-Gomes \\ Universidade Portucalense, Infante D. Henrique (PORTUGAL)
}

\begin{abstract}
The A3ES (Agency for the Evaluation and Accreditation of Higher Education), has as its mission to guarantee the quality of higher education in Portugal through the evaluation and accreditation of higher education institutions and their study cycles, as well as in the performance of the functions inherent in the insertion of Portugal in the European system of quality assurance of higher education, whether in the institutional scope or in the scope of quality all the HEls (Higher Education Institutions) in Portugal, whether public or private entities. With this work we will explore the perspective of the A3Es on the one hand, and on the other, the one of the HEls.
\end{abstract}

During the year 2018, all the HEls in Portugal were submitted to the so-called Institutional Accreditation, which had the objective of evaluating the quality of the performance of higher education institutions, by measuring the degree of fulfillment of their mission, through performance parameters related to their respective performance and results, and should be based on international best practices in this area, focusing on, inter alia, higher education institutions, their organizational units and the study cycles they offer or intend to achieve.

The objective of this evaluation is to improve the quality of higher education institutions, provide informed information to society about the same institutions and develop an internal institutional culture of quality assurance.

It also provides that accreditation is aimed at ensuring compliance with the minimum requirements leading to the official recognition of higher education establishments and their study cycles, within the framework of the quality assurance system for higher education, and is carried out based on quality evaluation (articles 5 and 6 of the Law no. 38/2007, of August 16).

The A3ES says that for an HEI to achieve the Institutional Accreditation, it must have implemented the Internal Quality Assurance System (IQAS), however the IQAS Accreditation is optional, being a "seal of trust" of the A3ES.

In this context, this study describes the practices developed by an IES accredited by the IQAS for 6 years, maximum time of accreditation, and accredited for 3 years by Institutional Accreditation. It is a private $\mathrm{HEI}$ accredited by the IQAS. It stands out as the results of this content analysis, the perception of the areas with the greatest need to be leveraged, the respective improvements to be applied as well as the mechanisms to be implemented. This study contributes to the good practices of IQAS seen by the experienced side of an accredited $\mathrm{HEl}$. It identifies the most critical and sensitive areas of education where a permanent effort of the QEO (Quality and Evaluation Office) is required in the monitoring of the permanent implementation in the perspective of continuous improvement and the constant creation of control mechanisms for its maintenance.

Keywords: Accreditation; Good habits; Institutional Evaluation; Institution of Higher Education; Internal Quality Assurance System.

\section{INTRODUCTION}

The A3ES within its mission has been creating tools for the HEls within their organizations and in particular in the implementation of their ICMS to use them in the best way, so that, when they are implemented in a sustained way. The next phase of your upkeep is as hard or harder than the previous one. Since we are talking about systems that never have an end, they feed on the principle of "continuous improvement" and opportunities for improvement. 
Thus, the A3ES provides to the Universities and Polytechnics, in Portugal excellent tools to help the implementation of the SIGQ. Lend your experience through your auditors, advise, follow through visits from CAEs.

A functioning IQAS will bring success to all levels of the organization. In its core, its performance, its relationship between employees in their environment with students who feel protected and with all their rights guaranteed. With a good quality in teaching, with a good relationship with the guardianship because it will imply that the norms will be always fulfilled and therefore, conjugate will give the unavoidable financial comfort of the accounts of the IE (Institution Entity).

We could stay here writing endless lines about the advantages of having an integrated and integrated IQAS within an organization, but it is enough to analyze the practical results of Portuguese Higher Education organizations that have them by comparison those that do not yet have them , and soon the advantages of the same are verified.

In fact, an IQAS is so complex and comprehensive that it is truly difficult to implement it in an organization. Let us see the first great effort to make is that it has to be fully assumed by the maximum hierarchy of the organization, and therefore, it must become an integral part of its strategic guidelines.

From then on, the IQAS will be implemented by all its areas of activity, from the business area itself, to all the other areas that support and render the services so that the business can flow with all the necessary supports for which it makes up in different areas.

The QEO, has a leverage character, accompanies what is to improve, perceives what is less well and tries to keep what is good. It seeks from the various owners of the processes, mainly in the management of teaching and research, to create systems that guarantee a continuous improvement, from the implementation of the system, to the present day that counts on its maintenance.

Having an A3ES accredited IQAS means that it is implemented effectively.

\subsection{Implementation}

The implementation phase should begin with the Strategic Guidance Lines established by the (IE) Institution Entity of the University each cycle. These are reflected in the Strategic Plan prepared by the Rectory in the medium term, translated into the Plan of Action for its exercise. This is broken down into Annual Activity Plans, in which are described, the activities for the pursuit of the objectives of quality management.

These objectives are planned and monitored through the PMP (Performance Monitoring Plans), PES (Performance Evaluation System) and PER (Performance Evaluation Regulation).

Here are described the goals, monitoring indicators, as well as those responsible for each process. The actions to follow the goals are planned in the annual activity plans.

An consultative body for quality has been created, where all the influencers of the pyramid are involved, who are part of the organization's team, including the student representatives.

This Council promotes evaluation and feedback of the IQAS through the implementation of the quality management policy commitments in its different departments and areas.

The QEO dynamizes, coordinates and monitors the IQAS. Its mission is to promote and dynamize across all areas of the Organization, the implementation, maintenance and adequacy of the Quality Management and Guarantee System (QMGS), proposing the introduction of measures / actions that promote the involvement of the entire Organization, in order to ensure the optimization of the service in conditions of Quality.

The Consultative Body ensures the strategic coordination of the QMGS. Its functional and operational coordination is the responsibility of the QEO.

In this structure are defined the typologies of processes, according to their nature and interaction with the student and other interested parties:

- Management - describe the activities inherent in strategic planning as well as management of the continuous improvement of the Organization

- Value Chain - set of processes that are the basis for the development of the mission of the University centered on the essential vectors of Teaching, Research and Internationalization. 
- Operational - a set of processes that are the basis for the performance of the processes of the value chain, include the availability of human, material, financial and infrastructural resources.

The heads of each functional area are the first responsible for quality, and should therefore promote in their area the involvement and dynamization of quality assurance processes.

\subsection{Accreditation}

The HEI should, after the implementation phase of the IQMS, move on to the accreditation phase, with the certification of ISO 9001: 2008, however making the transition from the standard to ISO 9001: 2015.

This certification must be transversal to all processes, that is, to the whole University. Thus, internal cross-sectional audits are carried out, which are kept permanently and subsequently with the fulfillment of external audits by the Certifying Entity, which audits are also maintained, which are real opportunities for continuous and fruitful improvement in their implementation.

Audits, both internal and external, serve to discipline, train, and are viewed by all employees as true formations and upgrades in order to be permanently prepared to respond in each area of which they are involved according to establishments established and known by them best practices to achieve the objectives of HEl.

When the HEl understood that it was already in a sufficiently mature phase since the implementation of the IQAS, in order to advance to the accreditation of the IQAS, it obtained accreditation for the maximum time that is 6 years with the A3ES.

The purpose of this evaluation was to improve the quality of HEls, to provide informed information to society about the same institutions and to develop an internal institutional culture of quality assurance.

With accreditation by the A3ES that is the Regulatory Entity in Higher Education, the organization is stronger on the one hand, but compromised by another. Stronger because it has been able to obtain a seal of quality, which allows it to develop its activity with this lever, namely to be subject to the obligatory institutional evaluation for all the establishments of Higher Education. This is successfully done. It is compromised, to a degree of exigency in its provision of services of high level, which forces it to be permanently to follow through mechanisms of control the efficiency of the SIGQ so that the objectives are reached.

\subsection{Maitenance}

The maintenance phase is possibly the most difficult since it requires not only the involvement of everyone as in the previous phase, but now all are active players without loss or omissions from all that are good practices, procedures, regulations, and other mechanisms created in the creation phase.

Experience tells us that the real effort made by an organization to certify and accredit its IQAS is not in its implementation but in its maintenance over time.

It is fundamental to incorporate a culture of quality into the routine of everyone in the organization. Thus, all the effort and investment made will be rewarded.

To this end, the QEO has created over time warning systems to anticipate possible nonconformities or sensitive areas. The tendency is to create habits that may lead to deviant behaviors that require continuous attention to keep the system with high quality standards. Especially in the area of teaching and research management.

The maintenance itself is the responsibility of each process owner, and there are four-month meetings to follow up the various results, by the advisory body.

At these meetings, PMP, PES and PER results and targets are verified, improvement opportunities are proposed for the goals not reached and indicators are adjusted.

In order to be successful, control tools have been created in various areas and processes. The control of these tools is done by each process owner and by the QEO, that feeling that there is recurrence in possible problems acts accordingly to fill them. The guarantor of maintenance is the performance of the internal and external audits that are performed several times throughout the year. The findings of these audits are analyzed by each process owner, QEO and top management of the organization, carrying out continuous improvement processes, immediate resolution of nonconformities and sensitive areas and implementation of improvement opportunities encountered. 
The HEI invested in the dematerialization of processes, alert systems and IT platforms in order to guarantee the best performance of its IQAS, with the objective of maintaining and ensuring these certifications and accreditations that for $\mathrm{HEl}$ are fundamental and basic for its continuity as an organization.

\section{METHODOLOGY}

This work was based on the option of the case study. In the field of social projects, the case study has become, in the last decades, a methodology for improving the work of non-governmental organizations and surveying new proposals for social intervention. It has become common in the 1990s to carry out exemplary case studies, whether from the point of view of its political or social aspect. The option for the case study was a conscious choice, since it was intended to investigate a situation that can not be understood from quantitative methods. Documents were analysed, and field notes were taken. The decision whether or not to carry out a case study was much more epistemological than methodological. In this study objectives focus on humanistic outcomes rather than behavioural outcomes or individual differences, information was subject to scrutiny based on credibility, and the chosen unit, The Portuguese HEI, in itself is a worthy case to be studied.

This $\mathrm{HEl}$ is a Portuguese Institution that began its academic activities, starting with an ambitious project. Build an institution where the search for and transmission of new knowledge, a goal so much of the vocation of a university, was associated with the deepening of the knowledge already made, to the tradition of a history and culture of many centuries, preparing young people for the challenges of modern times. At present, this HEl has approximately 235 collaborators, 150 teachers and 85 nonteaching staff. At present, the Institution has 5 Organic Units and 3 Research Centers, one of which is accredited by the Foundation for Science and Technology.

\section{RESULTS}

The results of this analysis of content, the perception of the areas with the greatest need to be leveraged, in this case Teaching and Research, are the respective improvements to be applied, as well as the mechanisms to be implemented.

Teaching aims to adopt the most appropriate procedures and ensure that it is taught in a way that favors an active role of the student in the creation of the learning process, as well as student evaluation processes that are consonant with this approach.

Taking into account the importance of evaluation in the progression of students and their future careers, the institution has mechanisms in place to ensure that student evaluation is carried out in accordance with previously defined and publicized criteria, standards and procedures, which are fairly applied and consistent.

With regard to Research, the HEI should be equipped with mechanisms to promote, evaluate and improve high-level scientific, technological and professional development activities appropriate to its institutional mission.

Having fulfilled the proposed objectives, ie ISO 9001 certification and accreditation of the IQAS, Institutional Accreditation, to which all HEls were subject, it happened with some tranquility satisfying the purpose of the 3-year accreditation.

\section{CONCLUSIONS}

A University in Portugal, having accredited its IQAS and the Institutional Assessment by the Regulatory Entity A3ES, acquires capacities to face the internal and external difficulties that the market demands to overcome them more easily than those that do not have these two certifications.

Regarding the first certification, once it is implemented, it can be concluded that it requires the involvement of all the active subjects in an organization, on the one hand, but on the other, it will endow it, as already mentioned means to achieve its objectives in a controlled, concrete and effective way. And over the years it will be an added value for the organization to broaden its horizons, grow in strategic, financial, and performance terms since as a player in the market, its services are surely differentiated among other requirements, too the quality. 
The Institutional Assessment means that the organization as a whole is in compliance with all that the tutelage understands as necessary to be in the market to administer the Higher Education with good practices, with good levels of investigation, with facilities and conformity with the system financial sustainability.

We can conclude that with the ISO 9001 quality certification and the accreditation of the SIGQ, the audits of the A3ES are smoother, as happened with the institutional evaluation, and what also happens in the evaluation of the courses. The A3ES considers that the HEls with these accreditations have a seal of confidence thus attenuating the various accreditations during the course of the course.

The HEl is subject to periodic external evaluation processes, in line with the European Standards and Guidelines for Higher Education (ESG).

The external evaluation, besides offering validated information that assures the $\mathrm{HEl}$ and the public the quality of the activities developed, verifies the effectiveness of the IQAS and acts as a catalyst for the improvement offering new perspectives to the institution.

\section{REFERENCES}

[1] A3ES (2013 maio, v.1.1). Manual de Avaliação, Agência de Avaliação e Acreditação do Ensino Superior, Lisboa. http://www.a3es.pt/pt/acreditacao-e-auditoria/manual-de-avaliacao.

[2] A3ES (2016 outubro, v.1.2). Manual da Qualidade, Agência de Avaliação e Acreditação do Ensino Superior, Lisboa. https://www.a3es.pt/sites/default/files/Manual\%20Auditoria_PT_V1.2_ Out2016.pdf.

[3] A3ES (2013, janeiro, v1.1). Guião para Elaboração do Relatório de Auditoria, Lisboa. https://www.a3es.pt/sites/default/files/Gui\%C3\%A3o_Relat\%C3\%B3rioCAE_ASIGQ_V1.1_Jan20 13.pdf

[4] A3ES (2017, janeiro, v1.0). Manual para o Processo de Avaliação Institucional no Ensino Superior, lisboa. https://www.a3es.pt/sites/default/files/Manual\%20Avalia\%C3\%A7\%C3\%A30\%20 Institucional_V1.0_Jan2017_0.pdf.

[5] A3ES (2017, junho). Guião para Elaboração do Relatório de Avaliação Institucional, Lisboa. https://www.a3es.pt/sites/default/files/Aval.Inst_-Univ-20.06.2017.pdf

[6] Costa-Lobo, C. \& Ferreira, A. T. (2012). Educação para a Carreira: Contributos para a Tomada de Decisão nas Transições Profissionais. In: Alves, J. S. \& Neto, A. M. S. (org.), Decisão: Percursos e Contextos (pp. 201-206). Vila Nova de Gaia: Eu Edito.

[7] Costa-Lobo, C. (2011). Abordagem sócio-cognitiva do ajustamento à carreira no ensino superior: o papel das actividades em grupo, da auto-eficácia e dos interesses (Tese de Doutoramento). Escola de Psicologia, Universidade do Minho, Braga, Portugal.

[8] ENQA, ESU, EUA \& EURASHE (2015). Standards and Guidelines for Quality Assurance in the European Higher Education Area (ESG). Brussels, Belgium.

[9] EUA (2003). Graz Declaration 2003 - Forward from Berlin: the Role of the Universities, European University Association, Brussels, September 2003.

[10] FINHEEC (2008). Audits of Quality Assurance Systems of Finnish Higher Education Institutions Audit Manual for 2008-2011, Finnish Higher Education Evaluation Council, Helsinki.

[11] Jesus-Silva, N., Medeiros, A. M., Caramelo-Gomes, J.; Costa- Lobo, C. (2016). Quality in higher education: analysis and discussion of evaluative standards internal consistency. Proceedings of ICERI 2016. ISBN: 978-84-617-5895-1.

[12] Santos (2011). Análise Comparativa dos Processos Europeus para a Avaliação e Certificação de Sistemas Internos de Garantia da Qualidade, A3ES Readings 1, Agência de Avaliação e Acreditação do Ensino Superior (A3ES), Lisboa. http://www.a3es.pt/sites/default/files/ ESTUDO_SIGQ_PT.pdf.

[13] Sá, E., Dias, D, \& Sá, M. J. (2017). Towards the university entrepreneurial mission: Portuguese academics' self-perspective of their role in knowledge transfer. Journal of Further and Higher Education, DOI: 10.1080/0309877X.2017.1311998. 
[14] Sousa, C., Magalhães, M., Castro Lopes, F., Fernandes, S., Costa-Lobo, C. (2017). EHIS Method(): Entrepreneurship Human Interaction Skills. In Christophe Loué \& Sonia Ben Slimane (Eds), Proceedings of the 12th European Conference on Innovation and Entrepreneurship ECIE 2017 (pp.644-652 ). Paris (France). ISBN: 978-1-911218-55-5. 